\title{
Cardiovascular risk factors and body composition in adults with achondroplasia
}

\author{
Svein O. Fredwall, MD ${ }^{1,2 凶}$, Jennifer Linge, $\mathrm{MSc}^{3,4}$, Olof Dahlqvist Leinhard, $\mathrm{PhD}^{3,4,5}$, Lisa Kjønigsen, $\mathrm{MSc}^{6}$,

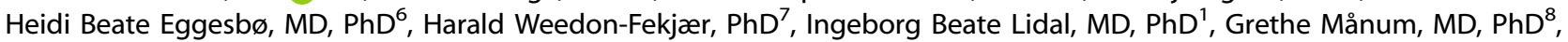 \\ Ravi Savarirayan, MBBS, $\mathrm{MD}^{9}$ and Serena Tonstad, MD, $\mathrm{PhD}^{10}$
}

\begin{abstract}
PURPOSE: An increased cardiovascular mortality has been reported in achondroplasia. This population-based, case-control study investigated cardiovascular risk factors and body composition in Norwegian adults with achondroplasia.

METHODS: We conducted anthropometric, clinical, and laboratory assessments in 49 participants with achondroplasia, of whom 40 completed magnetic resonance imaging (MRI) for body composition analysis. Controls consisted of 98 UK Biobank participants, matched for body mass index (BMI), sex, and age.

RESULTS: Participants were well matched for BMI (33.3 versus $\left.32.5 \mathrm{~kg} / \mathrm{m}^{2}\right)$ and sex, but achondroplasia participants were younger than controls (mean age 41.1 versus 54.3 years). Individuals with achondroplasia had lower age-adjusted mean blood pressure, total and low-density lipoprotein (LDL) cholesterol, and triglycerides compared with controls, but similar fasting glucose and $\mathrm{HbA} 1 \mathrm{c}$ values. Age-adjusted mean visceral fat store was 1.9 versus $5.3 \mathrm{~L}$ (difference $-2.7,95 \%$ confidence interval $[\mathrm{Cl}]-3.6$ to -1.9 ; $P<0.001)$, abdominal subcutaneous fat was 6.0 versus $11.2 \mathrm{~L}(-4.7,95 \% \mathrm{Cl}-5.9$ to $-3.4 ; P<0.001)$, and liver fat was 2.2 versus $6.9 \%$ $(-2.8,95 \% \mathrm{Cl}-5.2$ to $-0.4 ; P=0.02)$.

CONCLUSION: Despite a high BMI, the cardiovascular risks appeared similar or lower in achondroplasia compared with controls, indicating that other factors might contribute to the increased mortality observed in this condition.
\end{abstract}

Genetics in Medicine (2021) 23:732-739; https://doi.org/10.1038/s41436-020-01024-6

\section{INTRODUCTION}

Obesity is strongly associated with the development of hypertension, dyslipidemia, and type 2 diabetes mellitus (T2DM), leading to cardiovascular disease (CVD) and increased mortality. ${ }^{1-3}$ Obesity is a concern in achondroplasia, as individuals with this condition commonly have a body mass index (BMI) in the obesity range, with a predisposition to abdominal obesity. ${ }^{4-7}$ Some previous studies have reported an increased cardiovascular mortality in this condition. ${ }^{8}$ However, the correlation between BMI, cardiovascular risks, and body composition has not been investigated in detail in adults with achondroplasia. ${ }^{6,7,9}$

Achondroplasia is the most common cause of disproportionate short stature, and is caused by a gain-of-function pathogenic variant in the fibroblast growth factor receptor 3 (FGFR3) gene. ${ }^{10}$ The appendicular skeleton (arms and legs) is short, while the trunk is of almost average size. ${ }^{4,5}$ Life expectancy is almost normal, but a 10-year earlier mortality has been reported. ${ }^{8}$

Smoking, hypertension, dyslipidemia, and T2DM are major risk factors of CVD. ${ }^{11}$ Moreover, obesity, in particular excess of visceral abdominal fat and liver fat, are key predictive risk factors of CVD and T2DM, ${ }^{1,12,13}$ while subcutaneous fat deposition might have a protective effect. ${ }^{2,14} \mathrm{BMI}$ and waist circumference are commonly used anthropometric measurements to assess obesity in clinical practice. ${ }^{1,2,12}$ However, these measurements cannot predict individual fat distribution or liver fat deposition, nor distinguish visceral from subcutaneous adiposity. ${ }^{1,2,12}$ Moreover, assessment of obesity in achondroplasia remains challenging, due to the different body shape, and no established reference standards are available for adults with this condition. ${ }^{6,7}$

Magnetic resonance imaging (MRI) is currently regarded as the reference standard for body composition analysis. ${ }^{12,13,15}$ Recent developments of standardized acquisition protocols and automated image analysis for anatomical segmentations have enabled direct assessment and quantification of visceral, subcutaneous, and liver fat, fat-free muscle volume, and muscle fat infiltration. ${ }^{13,16-18}$ Reference values for average-sized adults are available from the UK Biobank Imaging Study. ${ }^{19,20}$

The objectives of the present study were to investigate cardiovascular risk factors and body composition, assessed by MRI, in Norwegian adults with achondroplasia. We also compared findings with population-based controls.

\section{MATERIALS AND METHODS}

\section{Study population}

This case-control study was part of The Norwegian Adult Achondroplasia Study, a population-based study conducted between 2017 and 2019 among 50 community-dwelling, Caucasian adults, 16 years of age or older, living in Norway. All participants had genetically confirmed achondroplasia. Details of the recruitment process, inclusion, and exclusion criteria have been described elsewhere. ${ }^{21}$

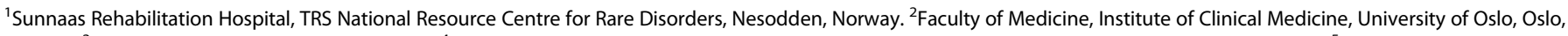

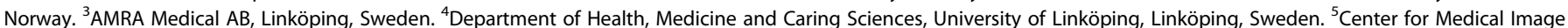

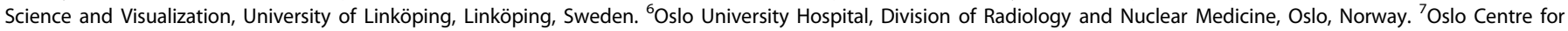

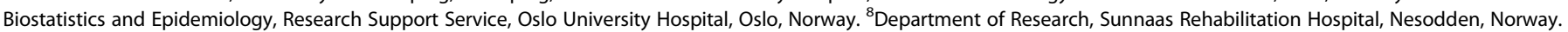
${ }^{9}$ Murdoch Children's Research Institute and University of Melbourne, Parkville, Australia. ${ }^{10}$ Department of Preventive Cardiology, Oslo University Hospital, Oslo, Norway.

email: svfred@sunnaas.no
} 


\begin{tabular}{ll|ll|ll|ll} 
BMI: & $28.2 \mathrm{~kg} / \mathrm{m}^{2}$ & BMI: & $39.2 \mathrm{~kg} / \mathrm{m}^{2}$ & BMI: & $36.4 \mathrm{~kg} / \mathrm{m}^{2}$ & BMI: & $43.8 \mathrm{~kg} / \mathrm{m}^{2}$ \\
VAT: & 0.27 liters & VAT: & 1.11 liters & VAT: & 3.23 liters & VAT: & $5.55 \mathrm{liters}$ \\
ASAT: & $\mathbf{3 . 0 2}$ liters & ASAT: & 11.38 liters & ASAT: & 9.77 liters & ASAT: & 9.05 liters \\
LF: & 1.89 liters & LF: & 2.06 liters & LF: & 1.77 liters & LF: & 6.57 liters \\
MFI: & $6.0 \%$ & MFI: & $12.1 \%$ & MFI: & $12.0 \%$ & MFI: & $14.5 \%$
\end{tabular}
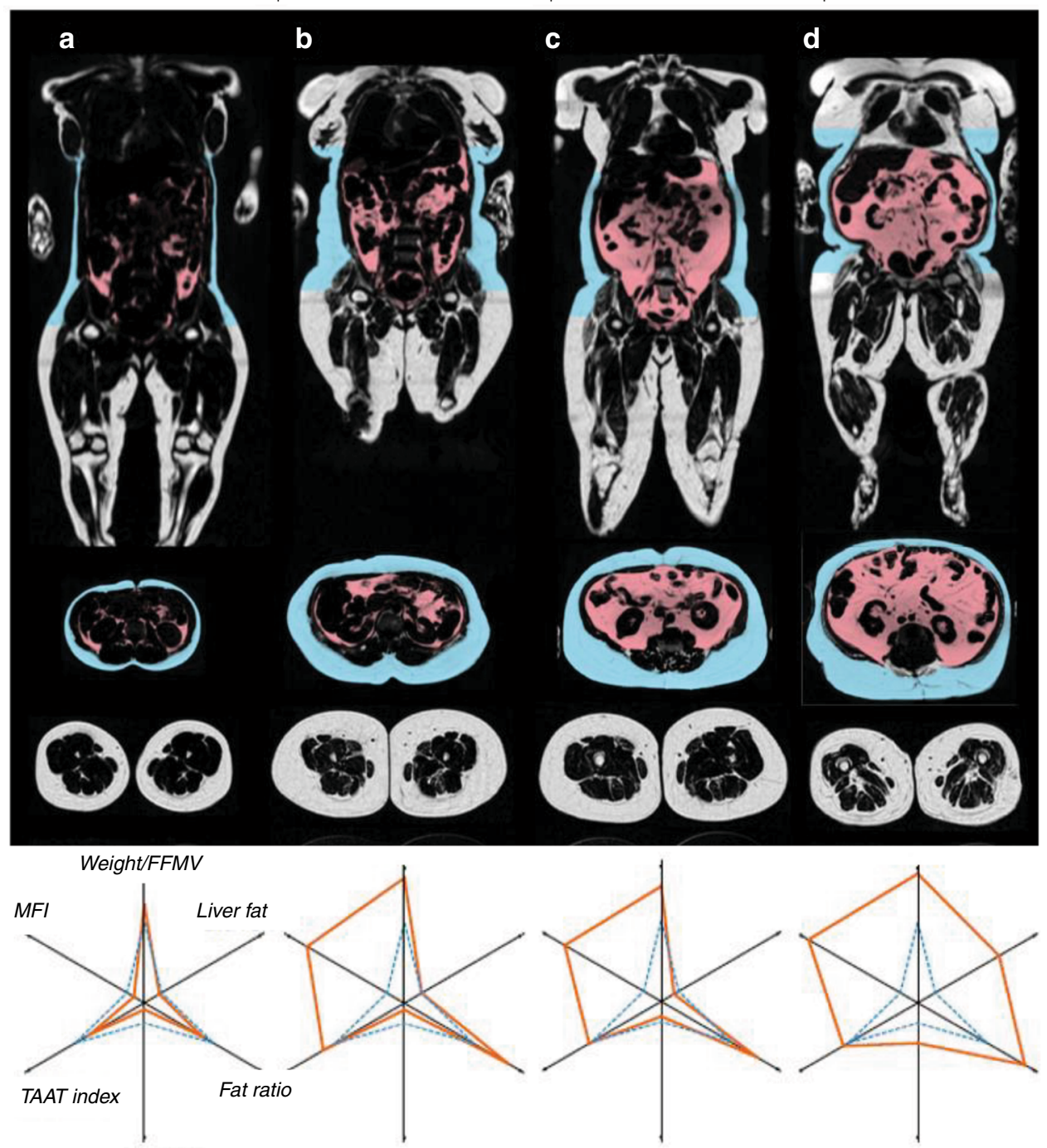

VAT index

Fig. 1 Body composition in four different individuals with achondroplasia. The coronal and abdominal axial magnetic resonance images show visceral adipose tissue (VAT) in red and abdominal subcutaneous adipose tissue (ASAT) in blue. Below, axial images of the thighs. At the bottom, the orange lines show the individual body composition profiles compared with reference values (blue dashed lines) based on median of the metabolic disease-free UK Biobank reference population $(n=2927)$. Individuals A, B, and C had low VAT, while individual B, C, and D had moderately increased ASAT. Increased liver fat was seen in individual D. Individuals B, C, and D had increased muscle fat infiltration (MFI). All four individuals had decreased fat-free muscle volume (FFMV), as reflected by the high weight/FFMV ratio. ASAT abdominal subcutaneous adipose tissue, BMI body mass index, FFMV fat-free muscle volume, LF liver fat, MFI muscle fat infiltration, TAAT total abdominal adipose tissue (VAT + ASAT), VAT visceral adipose tissue.

\section{Data collection and clinical measurements}

Demographical data was collected from The Norwegian Adult Achondroplasia Study. Clinical information was obtained by a face-to-face interview, and included a history of hypertension, diabetes, high cholesterol or coronary heart disease, current medication, and smoking habits.

Anthropometric measurements were conducted in the morning with the participants wearing light clothes and without shoes, and included height, sitting height, weight, and waist circumference. BMI was calculated as weight divided by height squared. Obesity was defined as $B M I \geq 30 \mathrm{~kg} / \mathrm{m}^{2}$, and severe obesity as BMI $\geq 40 \mathrm{~kg} / \mathrm{m}^{2}$. 22

Fasting venous blood samples were collected from all participants using serum gel tubes and EDTA anticoagulated blood tubes. The blood samples were analyzed for total cholesterol, LDL and HDL cholesterol, triglycerides, glucose, glycated hemoglobin ( $\mathrm{HbA} 1 \mathrm{c})$, and thyroid, liver, and kidney function, at the Laboratory of Clinical Chemistry, Oslo University Hospital.

Blood pressure was measured in the morning on the participant's right upper arm, using a digital blood pressure monitor (A\&D Medical Model UA767 Plus 30 ) with a commercially available, narrow, adult cuff. Participants were seated for a minimum of 30 minutes before the measurement. Blood pressure was measured three times, with one-minute waiting time between each measurement. A mean was calculated for the last two measurements, and rounded to the nearest whole value.

Hypertension was defined according to the European Society of Cardiology's 2018 guidelines as either systolic blood pressure $\geq 140 \mathrm{~mm}$ $\mathrm{Hg}$ or diastolic blood pressure $\geq 90 \mathrm{~mm} \mathrm{Hg},{ }^{23}$ or antihypertensive drug 
Table 1. Clinical characteristics of men and women with achondroplasia.

\begin{tabular}{|c|c|c|c|}
\hline Variables & $\begin{array}{l}\text { Men } \\
(n=27)\end{array}$ & $\begin{array}{l}\text { Women } \\
(n=22)\end{array}$ & $\begin{array}{l}\text { Difference } \\
(95 \% \mathrm{Cl})\end{array}$ \\
\hline & Mean (SD) & Mean (SD) & \\
\hline \multicolumn{4}{|l|}{ Anthropometrics } \\
\hline Body mass index, $\mathrm{kg} / \mathrm{m}^{2}$ & $34.0(7.6)$ & $32.4(5.6)$ & $1.6(-2.3$ to 5.5$)$ \\
\hline Sitting height, $\mathrm{cm}^{\mathrm{a}}$ & $87.0(4.6)$ & $85.0(3.6)$ & $1.9(-0.6$ to 4.4$)$ \\
\hline Weight, kg & $62.4(15.8)$ & $54.6(9.7)$ & $7.9(0.5$ to 15.3$)$ \\
\hline Medical history & $\%$ (number) & $\%$ (number) & \\
\hline Hypertension & $52 \%(14)$ & $14 \%(3)$ & $38 \%$ (10 to 66$)$ \\
\hline Current smoking & $15 \%(4)$ & $5 \%(1)$ & $10 \%(-10$ to 30$)$ \\
\hline Clinical findings & Mean (SD) & Mean (SD) & \\
\hline Systolic blood pressure, $\mathrm{mm} \mathrm{Hg}$ & $125.3(16.5)$ & $117.6(14.3)$ & $7.7(-1.3$ to 16.7$)$ \\
\hline Diastolic blood pressure, $\mathrm{mm} \mathrm{Hg}$ & $76.6(11.4)$ & $73.2(9.9)$ & $3.4(-2.8$ to 9.6$)$ \\
\hline Total cholesterol, mmol/L & $4.5(1.0)$ & $4.9(0.9)$ & $-0.3(-0.9$ to 0.2$)$ \\
\hline $\mathrm{HDL}$ cholesterol, $\mathrm{mmol} / \mathrm{L}^{\mathrm{b}}$ & $1.3(0.3)$ & $1.5(0.5)$ & $-0.3(-0.5$ to -0.02$)$ \\
\hline LDL cholesterol, $\mathrm{mmol} / \mathrm{L}^{\mathrm{b}}$ & $2.9(0.9)$ & $3.0(0.6)$ & $-0.08(-0.5$ to 0.4$)$ \\
\hline Triglycerides, $\mathrm{mmol} / \mathrm{L}$ & $1.2(0.6)$ & $1.0(0.4)$ & $0.3(-0.05$ to 0.6$)$ \\
\hline Glucose, $\mathrm{mmol} / \mathrm{L}^{\mathrm{c}}$ & $5.2(0.9)$ & $4.8(0.4)$ & $0.4(-0.05$ to 0.8$)$ \\
\hline Muscle fat infiltration, $\%$ & $10.8(6.5)$ & $9.9(2.3)$ & $0.9(-2.2$ to 4.0$)$ \\
\hline
\end{tabular}

Data presented are mean and standard deviation (SD) for continuous variables, and percent and observed numbers for proportions.

$C /$ confidence interval, $H D L$ high-density lipoprotein, $L D L$ low-density lipoprotein.

${ }^{\mathrm{a}}$ Men $n=25$, women $n=21$.

${ }^{\mathrm{b}}$ Men $n=27$, women $n=21$.

${ }^{\mathrm{c}}$ Men $n=26$, women $n=21$.

${ }^{\mathrm{d}}$ Men $n=19$.

${ }^{\mathrm{e}}$ Total abdominal fat: visceral fat + abdominal subcutaneous fat.

f Men $n=19$, women $n=19$.

treatment. T2DM was defined according to the American Diabetes Association as $\mathrm{HbA1c} \geq 6.5 \%$ ( $48 \mathrm{mmol} / \mathrm{L})$ or fasting plasma glucose $\geq 7$ $\mathrm{mmol} / \mathrm{L},{ }^{24}$ the use of antidiabetic drugs, or a medical history of diabetes.

\section{Body composition assessment}

We used a 3 T MRI scanner (Discovery 750, GE Healthcare) with a 32channel body array coil. Two sequences were used: LAVA flex (3D imaging) and IDEAL IQ sequence. The scan area was from the upper level of vertebra T9 to the ankle, with total scanning time six minutes. Body composition analysis was performed by using the AMRA Profiler Research (AMRA Medical AB, Linköping, Sweden). ${ }^{13,16,17}$ The MRI scans were analyzed for visceral and abdominal subcutaneous fat, liver proton density fraction (liver fat), fat-free thigh muscle tissue volumes in anterior and posterior compartments, and muscle fat infiltration in the anterior thighs for at least one leg. ${ }^{13,16,17}$ Following the automated segmentation and analysis process, an experienced operator reviewed each segmentation for anatomical correctness and technical quality. A body composition profile was made for each participant (with examples given in Fig. 1), and for the total study population who completed the MRI scans. ${ }^{16,19}$

Liver fat images were technically satisfactory in all participants with achondroplasia completing MRI $(n=40)$. For visceral and subcutaneous fat assessment, 39 of 40 scans were technically satisfactory, as for muscle fat infiltration and thigh muscle volumes for both legs in 38 scans, and for one leg in the remaining two scans. 


\section{Control group}

Achondroplasia participants were compared with sex and BMI-matched controls (1:2) from the UK Biobank database $(n=9604) .^{20}$ The age distribution (45 to 79 years) in the UK Biobank population did not allow perfect matching with regard to age. Controls were required to have nonmissing data for sex, age, weight, height, and complete body composition profile data (visceral and subcutaneous fat, liver fat, fat-free muscle volume, and muscle fat infiltration of at least one leg). Metabolic disease-free UK Biobank participants (used for reference values in the body composition profile) were defined according to Linge et al., ${ }^{19}$ and had a prevalence of $31 \%$ in the UK Biobank population $(n=2927)$. The groups were visualized using the body composition profile plot according to Linge et al. ${ }^{19}$ Sitting height was used instead of height as a standardization variable.

Scanning in the UK Biobank Imaging Study was performed using a Siemens MAGNETOM Aera 1.5 T MRI scanner (Siemens Healthineers, Erlangen, Germany). UK Biobank data was accessed through access application with project ID 6569. The same measurement software was used to analyze the images both in our study and in the UK Biobank study. ${ }^{19}$

\section{Statistical analysis}

Descriptive statistics are presented as means with standard deviation (SD) for continuous variables, and frequencies $(n)$ with percentages (\%) for proportions. Group differences are presented with 95\% independent samples $t$-tests confidence intervals $(\mathrm{Cl})$, and $p$ values, for continuous variables. Score $95 \% \mathrm{Cl}$ and continuity corrected chi-squared tests are given for proportions (applying the "prop. test" R function). Since perfect matching by age was not possible, linear mixed effects regression analysis was applied to adjust for age differences between UK Biobank controls and participants with achondroplasia, taking into account the variation in observed levels across different matched pairs. Statistical analysis was performed using R version 3.4.4 (The R Foundation, Vienna, Austria) and SPSS version 25 (IBM Corp., Armonk, NY).

\section{RESULTS}

Clinical characteristics of individuals with achondroplasia

Forty-nine of the 50 participants in The Norwegian Adult Achondroplasia Study were included in this study $(27 \mathrm{men}$ and 22 women). One declined participation. Mean BMI was $33.3 \mathrm{~kg} / \mathrm{m}^{2}$, ranging from 22 to $50 \mathrm{~kg} / \mathrm{m}^{2}$. Obesity $\left(B M I \geq 30 \mathrm{~kg} / \mathrm{m}^{2}\right)$ was found in $67 \%$ of the participants with achondroplasia, and $18 \%$ had severe obesity (BMI $\geq 40 \mathrm{~kg} / \mathrm{m}^{2}$ ).

Hypertension was found in $52 \%$ of the men and $14 \%$ of the women (Table 1). All but one had mild hypertension (systolic blood pressure 140 to $159 \mathrm{~mm} \mathrm{Hg}$ and/or diastolic blood pressure 90 to $99 \mathrm{~mm} \mathrm{Hg}$ ). In hypertensive participants, mean (SD) BMI was 37.8 (6.6) kg/m $\mathrm{m}^{2}$, compared with $31.0(5.7) \mathrm{kg} / \mathrm{m}^{2}$ in normotensive participants. Mean difference was $6.5 \mathrm{~kg} / \mathrm{m}^{2}$ (95\% Cl 3.2 to $10.4 \mathrm{~kg} /$ $\left.\mathrm{m}^{2} ; P<0.001\right)$. Correspondingly, mean waist circumference was $98.2(14.1) \mathrm{cm}$ versus $81.3(11.1) \mathrm{cm}$, with a mean difference of $16.9 \mathrm{~cm}(95 \% \mathrm{Cl} 9.5$ to $24.3 \mathrm{~cm} ; P<0.001)$. Three participants had T2DM, all with BMls $\geq 43 \mathrm{~kg} / \mathrm{m}^{2}$ and waist circumferences $\geq 107 \mathrm{~cm}$. Two participants had a history of coronary heart disease. Five participants (10\%) were current smokers, while 17 (35\%) were former smokers.

Mean lipid, glucose, and $\mathrm{HbA} 1 \mathrm{c}$ levels were all within the recommended range for both genders, according to the guidelines provided by the European Society of Cardiology ${ }^{11}$ (Table 1). The liver, kidney, and thyroid function were also within normal limits (data not shown). There were no differences between men and women with achondroplasia regarding sitting height, BMI, blood pressure, total and LDL cholesterol, triglycerides, glucose, and $\mathrm{HbA} 1 \mathrm{c}$ (Table 1).

Body composition in individuals with achondroplasia MRI was completed in 20 men and 20 women with achondroplasia (Table 1). Nine participants were unable to complete MRI, as they failed the pre-MRI safety checklist (non-MRI compatible shunt, devices or metal implants, or not able to lie on their back; $n=4$ ), or were visited in their homes due to impaired mobility $(n=5)$. Those who completed MRI $(n=40)$ were younger than those who did not $(n=9)$, but there were no considerable differences regarding $\mathrm{BMI}$, waist circumference, blood pressure, fasting lipids, and glucose levels between the two groups (Table 2).

Visceral and abdominal subcutaneous fat, liver fat, and total abdominal fat stores were low in individuals with achondroplasia, with values close to the metabolic disease-free UK Biobank reference population. Fat-free thigh muscle volume was reduced,

Table 2. Comparison between adults with achondroplasia who completed or not completed body composition magnetic resonance imaging (MRI).

\begin{tabular}{|c|c|c|c|c|}
\hline \multirow[t]{2}{*}{ Variables } & \multicolumn{4}{|c|}{ Completed MRI } \\
\hline & $\begin{array}{l}\text { Yes } \\
\text { Mean (SD) }\end{array}$ & $\begin{array}{l}\text { No } \\
\text { Mean (SD) }\end{array}$ & $\begin{array}{l}\text { Mean difference } \\
(95 \% \mathrm{Cl})\end{array}$ & $P$ value \\
\hline Age, years & $37.0(16.7)$ & $59.2(18.0)$ & $-22.2(-34.8$ to -9.6$)$ & 0.001 \\
\hline Body mass index, $\mathrm{kg} / \mathrm{m}^{2}$ & $33.3(6.5)$ & $33.4(8.4)$ & $-0.1(-5.2$ to 4.9$)$ & 0.96 \\
\hline Diastolic blood pressure, $\mathrm{mm} \mathrm{Hg}$ & $75.0(11.7)$ & $75.2(5.9)$ & $-0.2(-8.3$ to 7.9$)$ & 0.96 \\
\hline Total cholesterol, $\mathrm{mmol} / \mathrm{l}$ & $4.6(1.0)$ & $5.0(0.8)$ & $-0.3(-1.1$ to 0.4$)$ & 0.33 \\
\hline $\mathrm{HDL}$ cholesterol, $\mathrm{mmol} / \mathrm{I}^{\mathrm{a}}$ & $1.4(0.4)$ & $1.2(0.2)$ & $0.2(-0.1$ to 0.5$)$ & 0.18 \\
\hline $\mathrm{LDL}$ cholesterol, $\mathrm{mmol} / \mathrm{I}^{\mathrm{a}}$ & $2.9(0.8)$ & $3.1(0.6)$ & $-0.2(-0.8$ to 0.4$)$ & 0.48 \\
\hline
\end{tabular}

$C /$ confidence interval, $H D L$ high-density lipoprotein, $L D L$ low-density lipoprotein, MRI magnetic resonance imaging.

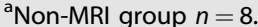

${ }^{b}$ Non-MRI group $n=7$. 
Table 3. Comparison between adults with achondroplasia (ACH) and UK Biobank (UKB) controls.

\begin{tabular}{|c|c|c|c|c|c|}
\hline Variables & $\begin{array}{l}\text { ACH } \\
\text { Mean (SD) }\end{array}$ & $\begin{array}{l}\text { Controls } \\
\text { Mean (SD) }\end{array}$ & $\begin{array}{l}\text { Unadjusted } \\
\text { Mean difference }(95 \% \mathrm{Cl})\end{array}$ & $\begin{array}{l}\text { Adjusted for age } \\
\text { Mean difference }(95 \% \mathrm{Cl})\end{array}$ & $P$ value \\
\hline Clinical variables & $(n=49)$ & $(n=98)$ & & & \\
\hline Age, year & $41.1(18.9)$ & $54.3(7.9)$ & $-13.2(-15.9$ to -10.5$)$ & - & - \\
\hline Women,\% & 44.9 & 44.9 & 0 [matched] & - & - \\
\hline Height, $\mathrm{cm}$ & $132.9(8.9)$ & $171.4(8.8)$ & $-38.5(-40.9$ to -36.2$)$ & $-37.8(-40.6$ to -34.9$)$ & $<0.001$ \\
\hline Sitting height, $\mathrm{cm}^{\mathrm{a}}$ & $86.1(4.3)$ & $90.7(4.7)$ & $-4.6(-5.9$ to -3.3$)$ & $-5.2(-6.9$ to -3.6$)$ & $<0.001$ \\
\hline Weight, kg & $58.9(13.8)$ & $95.5(18.1)$ & $-36.6(-39.5$ to -33.6$)$ & $-35.0(-38.9$ to -31.1$)$ & $<0.001$ \\
\hline Systolic blood pressure, $\mathrm{mm} \mathrm{Hg}$ & $121.9(15.9)$ & $137.2(18.3)$ & $-15.4(-21.0$ to -9.8$)$ & $-11.6(-18.0$ to -5.1$)$ & 0.001 \\
\hline LDL cholesterol, mmol/ $\mathrm{L}^{\mathrm{b}}$ & $2.9(0.8)$ & $3.7(0.8)$ & $-0.7(-1.0$ to -0.5$)$ & $-0.6(-0.9$ to -0.3$)$ & $<0.001$ \\
\hline Triglycerides, $\mathrm{mmol} / \mathrm{L}$ & $1.1(0.5)$ & $2.2(1.5)$ & $-1.1(-1.5$ to -0.7$)$ & $-0.9(-1.4$ to -0.4$)$ & $<0.001$ \\
\hline Glucose, $\mathrm{mmol} / \mathrm{L}^{\mathrm{c}}$ & $5.1(0.7)$ & $5.0(1.1)$ & $0.1(-0.3$ to 0.4$)$ & $0.3(-0.1$ to 0.7$)$ & 0.12 \\
\hline $\mathrm{HbA} 1 \mathrm{c}, \mathrm{mmol} / \mathrm{mol}$ & $31.6(5.4)$ & $34.5(4.3)$ & $-2.9(-4.3$ to -1.4$)$ & $-0.9(-2.6$ to 0.7$)$ & 0.26 \\
\hline Body composition & $(n=40)$ & $(n=80)$ & & & \\
\hline \multicolumn{6}{|l|}{ Matched variables } \\
\hline Age, years & $37.0(16.7)$ & $52.8(5.8)$ & $-15.8(-18.8$ to -12.9$)$ & - & - \\
\hline Women, \% & 50 & 50 & 0 [matched] & - & - \\
\hline Body mass index, $\mathrm{kg} / \mathrm{m}^{2}$ & $33.3(6.5)$ & $32.6(5.5)$ & 0.7 (0.2 to 1.2$)$ & 1.6 (0.8 to 2.4$)$ & $<0.001$ \\
\hline $\begin{array}{l}\text { Differences between groups are pre } \\
H D L \text { high-density lipoprotein, } L D L \text { lo } \\
{ }^{\mathrm{a}} \mathrm{ACH} n=46 . \\
{ }^{\mathrm{b}} \mathrm{ACH} n=48 . \\
{ }^{\mathrm{c}} \mathrm{ACH} n=47 . \\
{ }^{\mathrm{d}} \mathrm{ACH} n=39 . \\
{ }^{\mathrm{e}} \text { Total abdominal fat: visceral fat }+ \\
{ }^{\mathrm{f}} \mathrm{ACH} n=38 .\end{array}$ & $\begin{array}{l}\text { ed as means wit } \\
\text { ensity lipoprotein }\end{array}$ & 95\% confidence i & terval $(95 \% \mathrm{Cl})$ & & \\
\hline
\end{tabular}

and muscle fat infiltration in the anterior thigh muscles was increased (Table 1).

Only five individuals with achondroplasia had visceral or liver fat values above metabolic disease-free UK Biobank reference values, all but one with BMls $\geq 40 \mathrm{~kg} / \mathrm{m}^{2}$ and waist circumferences $\geq 105$ centimeters. Visceral fat deposition and fat-free thigh muscle volumes were higher in men than in women with achondroplasia, while there were no considerable differences regarding liver fat, abdominal subcutaneous fat, and muscle fat infiltration (Table 1).

Comparison between individuals with achondroplasia and controls

Hypertension was found in $35 \%(n=17)$ of individuals with achondroplasia compared with $22 \%$ in UK Biobank controls, a difference of $13 \%(95 \% \mathrm{Cl}-5.0$ to $29.5 ; P=0.17)$. Waist circumference, systolic and diastolic blood pressure, total and LDL cholesterol, triglycerides, $\mathrm{HbA} 1 \mathrm{c}$, visceral, subcutaneous, liver, and total abdominal fat depots were all lower in participants with achondroplasia compared with the matched controls (Table 3 ). The participants with achondroplasia had lower fat-free thigh muscle volume and increased muscle fat infiltration in the anterior thighs, compared with the controls. The differences between individuals with achondroplasia and controls persisted also after adjusting for age (Table 3).

Figure 2 shows the body composition profile for participants with achondroplasia (green) compared with UK Biobank controls (red). 


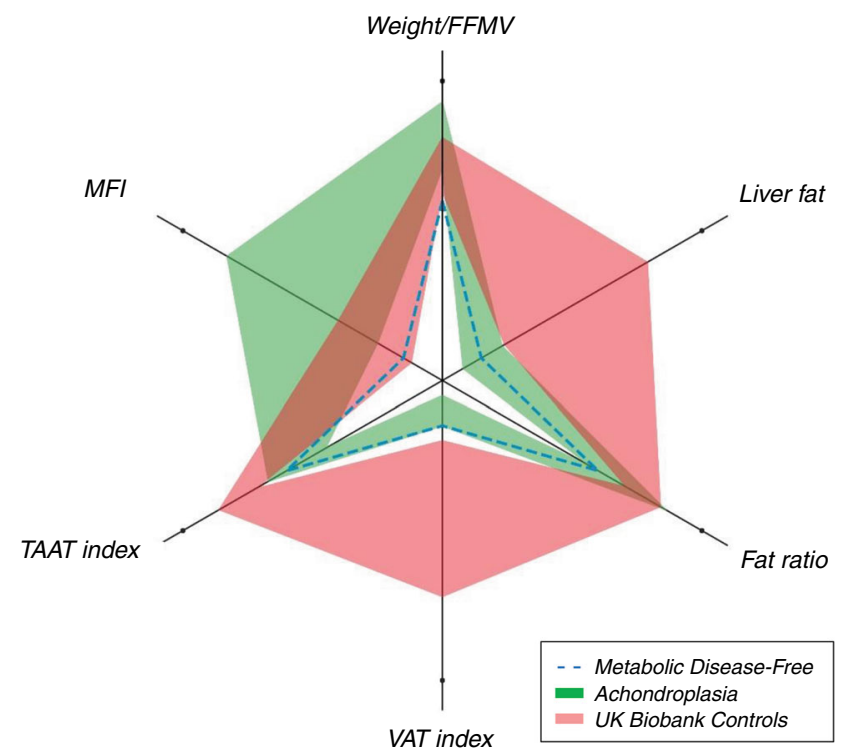

Fig. 2 Body composition profiles in achondroplasia compared with UK Biobank controls. The body composition profile in the achondroplasia group (green; $n=40$ ) indicates a low propensity of developing type 2 diabetes and cardiovascular disease, in contrast to the BMI-matched controls (red; $n=80$ ). Shaded fields are covering the interquartile ranges. Dashed blue lines are reference values based on median of the metabolic disease-free UK Biobank population $(n=2927)$. FFMV fat-free muscle volume, MFI muscle fat infiltration, TAAT total abdominal adipose tissue (VAT + abdominal subcutaneous adipose tissue), VAT visceral adipose tissue.

\section{DISCUSSION}

In this study, more than two-thirds of the men and women with achondroplasia had a BMI in the obesity range $\left(\geq 30 \mathrm{~kg} / \mathrm{m}^{2}\right)$. Despite the high BMI, they had lower blood pressure, and lower atherogenic lipid levels, visceral and abdominal subcutaneous fat stores, and liver fat, than BMI-matched average-statured controls. Their glucose-related parameters were similar to those observed in the controls. Fat-free thigh muscle volume was lower and muscle fat infiltration was higher than controls.

The negative influence of obesity on cardiovascular risk factors is well established, including increased blood pressure, dyslipidemia, insulin resistance, and T2DM. ${ }^{1,2,12}$ In particular, excess visceral and liver fat are associated with cardiometabolic lipid abnormalities and T2DM, including those indicative of metabolic syndrome (low HDL cholesterol, high triglycerides, and small dense LDL particles). ${ }^{2,15}$ MRI affords the opportunity of direct assessment and visualization of body fat content and distribution, including ectopic fat deposits around the viscera and in the liver. ${ }^{13,15,18,20}$

Despite a mean BMI in the obesity range, participants with achondroplasia in the present study had low levels of atherogenic lipids (total and LDL cholesterol), low levels of triglycerides, and HDL cholesterol levels within the normal range. Their distribution of ectopic fat depots was close to the metabolic disease-free UK Biobank reference population. In contrast, UK Biobank controls, with similar BMls to the participants with achondroplasia, had elevated LDL cholesterol and triglyceride levels, and a body composition profile consistent with an increased propensity of developing CVD and T2DM. ${ }^{18-20}$

Our findings are consistent with the study by Owen et al., who found low triglyceride and glucose levels in 32 adults with achondroplasia. ${ }^{25}$ These findings are also consistent with a study in achondroplasia mice who developed an abdominal obesity, but not associated with diabetes or dyslipidemia. ${ }^{26}$

In our study, only three individuals with achondroplasia had T2DM, all with BMls $\geq 43 \mathrm{~kg} / \mathrm{m}^{2}$ and waist circumferences $\geq 107$ centimeters. The numbers are too small to draw definite conclusions about prevalence of T2DM in this condition, but indicate that metabolic complications can occur in achondroplasia in those with very high BMI and waist circumference. Thus, keeping a healthy diet, and maintaining regular physical activity, apply to people with achondroplasia, as for all people, to prevent excessive weight gain. ${ }^{6,12,27}$

The controls were older than the participants with achondroplasia. This might affect the outcome, as cardiovascular risk factors including lipid levels tend to increase with age. ${ }^{11,28,29}$ However, the differences between the two groups persisted also after adjusting for age.

While blood pressure levels were lower in the sample with achondroplasia than controls, hypertension was prevalent, particularly in men. Hypertension was found in $35 \%$ of the participants with achondroplasia, including $52 \%$ of the men. In a recently published US study, $56 \%$ of the men and $35 \%$ of the women with achondroplasia had hypertension. ${ }^{30}$ In the US study, hypertensive participants had significantly higher BMI than normotensive (BMI $38 \mathrm{~kg} / \mathrm{m}^{2}$ versus $32 \mathrm{~kg} / \mathrm{m}^{2}$ ), which is consistent with our findings.

Almost all hypertensive individuals with achondroplasia in our study had mild hypertension, of whom less than half used antihypertensive drugs. This could explain the somewhat paradoxical findings of high prevalence of hypertension, but low mean blood pressure. Hoover-Fong et al. have described challenges in obtaining an accurate blood pressure in some individuals with achondroplasia, due to short and contracted upper arms. ${ }^{30}$ In our study, we were able to obtain an adequate measurement in all participants by applying a commercially available, narrow adult cuff. As there are no specific reference standards for defining hypertension in achondroplasia, we have applied the same definition as for average-statured individuals. ${ }^{23}$ This definition was also used in the large US blood pressure study in skeletal dysplasia, including 234 adults with achondroplasia. ${ }^{30}$

Smoking is a well-established risk factor for cardiovascular disease. In our study, about $10 \%$ of the participants with achondroplasia were current smokers, which is similar to the general Norwegian population. ${ }^{31}$

The findings of reduced fat-free thigh muscle volume in achondroplasia has previously been reported in a small study by Sims et al. ${ }^{32,33}$ They assessed muscle architecture and body composition by ultrasound and dual X-ray absorptiometry in ten young men with achondroplasia, and found reduced muscle volume and muscle force in the lateral quadriceps muscle, compared with average-statured controls. The pathophysiology is unknown, but the authors suggested that increased muscle fat infiltration could be one explanation. ${ }^{32}$ Increased muscle fat infiltration has been associated with aging, physical inactivity, T2DM, and spinal cord injury in average-statured individuals, ${ }^{34,35}$ but the mechanisms and clinical implications in achondroplasia require further study.

\section{Strengths and limitations}

Among the strengths of this study were the objective measurements of body composition by MRI, comparison with a matched control group, participants being recruited from the community, and genetically confirmed achondroplasia in all participants. The choice of controls was based on the availability of data on body composition using the same methodology. Lipid and blood pressure measurements in UK Biobank controls were similar to the findings in the population-based Norwegian HUNT 2 study $(n=60,731),{ }^{36}$ confirming that the UK Biobank controls used in our study are comparable with the Norwegian general population.

Height, weight, and sitting height in our study were similar to data from a large Scandinavian-German cohort with achondroplasia. ${ }^{4,5}$ Hence, our study population is likely to be representative 
of achondroplasia adults in general regarding anthropometry, body proportions, and body composition.

There are also several limitations to this study. First, due to the relatively small sample size, our findings need to be confirmed in larger studies with more participants. Second, the comparison of the body composition between the achondroplasia population and UK Biobank controls was based on the assumption that the trunk size is approximately the same in achondroplasia as for the average-statured population. ${ }^{4,5}$ The mean (SD) sitting height in participants with achondroplasia was $86.1(4.3) \mathrm{cm}$, compared with $90.7(4.7) \mathrm{cm}$ in the controls. We considered this difference acceptable for performing comparisons between the two groups. Finally, the difference in age between the participants with achondroplasia and the controls, and between participants with achondroplasia completing MRI and not, could potentially affect the outcomes.

\section{Future research}

There are no established standards of evaluating obesity in adults with achondroplasia. ${ }^{6,7}$ This study has introduced MRI scanning as a possible modality for an individual assessment of body composition and cardiovascular risk in this condition. However, further studies are required to validate this method in achondroplasia, and to establish the prevalence of T2DM in this condition. The observed changes in the muscles in achondroplasia also require further study. Moreover, the unique cardiovascular risk pattern and metabolism in achondroplasia are not fully understood. A recent study on a mouse model of achondroplasia has suggested a direct relationship to the FGFR3 pathogenic variant and consequent downstream signaling. ${ }^{6,26}$ New therapies are currently being trialed for children with achondroplasia, targeting the FGFR3-signaling pathways. ${ }^{37,38}$ These potential treatments might also affect the metabolic profiles and body composition in achondroplasia, as demonstrated in the mouse model. ${ }^{26}$

\section{Conclusions}

Despite a mean BMI in the obesity range, individuals with achondroplasia had lower blood pressure, atherogenic lipids, and visceral, subcutaneous, and liver fat than BMI-matched averagestatured controls, while glucose-related parameters were similar. The cardiovascular risks appeared similar or lower in achondroplasia compared with controls, indicating that there might be other factors contributing to the increased mortality observed in this condition. This study supports growing evidence that BMI is not a clinically useful measure to assess cardiovascular risks in adults with achondroplasia. The assessment of body composition analysis by MRI might be a more sensitive modality to assess cardiovascular risks in this population, but needs to be further validated.

\section{DATA AVAILABILITY}

De-identified individual participant data are available from the corresponding author on reasonable request.

Received: 15 August 2020; Revised: 9 October 2020; Accepted: 21 October 2020;

Published online: 18 November 2020

\section{REFERENCES}

1. Després, J. P. Body fat distribution and risk of cardiovascular disease: an update. Circulation 126, 1301-1313 (2012)

2. Piché, M. E., Poirier, P., Lemieux, I. \& Després, J. P. Overview of epidemiology and contribution of obesity and body fat distribution to cardiovascular disease: an update. Prog. Cardiovasc. Dis. 61, 103-113 (2018).
3. Yusuf, S. et al. Effect of potentially modifiable risk factors associated with myocardial infarction in 52 countries (the INTERHEART study): case-control study. Lancet 364, 937-952 (2004).

4. Merker, A. et al. Development of body proportions in achondroplasia: sitting height, leg length, arm span, and foot length. Am. J. Med. Genet. Part A 176, 1819-1829 (2018).

5. Merker, A. et al. Growth in achondroplasia: development of height, weight, head circumference, and body mass index in a European cohort. Am. J. Med. Genet. Part A 176, 1723-1734 (2018).

6. Saint-Laurent, C., Garde-Etayo, L. \& Gouze, E. Obesity in achondroplasia patients: from evidence to medical monitoring. Orphanet J. Rare Dis. 14, 253 (2019).

7. Schulze, K. J., Alade, Y. A., McGready, J. \& Hoover-Fong, J. E. Body mass index (BMI): the case for condition-specific cut-offs for overweight and obesity in skeletal dysplasias. Am. J. Med. Genet. Part A 161a, 2110-2112 (2013).

8. Wynn, J., King, T. M., Gambello, M. J., Waller, D. K. \& Hecht, J. T. Mortality in achondroplasia study: a 42-year follow-up. Am. J. Med. Genet. Part A 143A, 2502-2511 (2007).

9. Fredwall, S. O. et al. Current knowledge of medical complications in adults with achondroplasia: a scoping review. Clin. Genet. 97, 179-197 (2020).

10. Ornitz, D. M. \& Legeai-Mallet, L. Achondroplasia: development, pathogenesis, and therapy. Dev. Dyn. 246, 291-309 (2017).

11. Piepoli, M. F. et al. 2016 European Guidelines on cardiovascular disease prevention in clinical practice: The Sixth Joint Task Force of the European Society of Cardiology and Other Societies on Cardiovascular Disease Prevention in Clinical Practice (constituted by representatives of 10 societies and by invited experts). Developed with the special contribution of the European Association for Cardiovascular Prevention \& Rehabilitation (EACPR). Eur. Heart J. 37, 2315-2381 (2016).

12. Cornier, M. A. et al. Assessing adiposity: a scientific statement from the American Heart Association. Circulation 124, 1996-2019 (2011).

13. Borga, M. et al. Advanced body composition assessment: from body mass index to body composition profiling. J. Invest. Med. 66, 1-9 (2018).

14. Vasan, S. K. et al. Comparison of regional fat measurements by dual-energy X-ray absorptiometry and conventional anthropometry and their association with markers of diabetes and cardiovascular disease risk. Int. J. Obes. 42, 850-857 (2018).

15. Thomas, E. L., Fitzpatrick, J. A., Malik, S. J., Taylor-Robinson, S. D. \& Bell, J. D. Whole body fat: content and distribution. Prog. Nucl. Magn. Reson. Spectrosc. 73, 56-80 (2013).

16. West, J. et al. Feasibility of MR-based body composition analysis in large scale population studies. PLOS ONE 11, e0163332 (2016).

17. Karlsson, A. et al. Automatic and quantitative assessment of regional muscle volume by multi-atlas segmentation using whole-body water-fat MRI. J. Magn. Reson. Imaging 41, 1558-1569 (2015).

18. Neeland, I. J., Poirier, P. \& Després, J. P. Cardiovascular and metabolic heterogeneity of obesity: clinical challenges and implications for management. Circulation 137, 1391-1406 (2018).

19. Linge, J. et al. Body composition profiling in the UK Biobank Imaging Study. Obesity 26, 1785-1795 (2018).

20. Linge, J., Whitcher, B., Borga, M. \& Dahlqvist Leinhard, O. Sub-phenotyping metabolic disorders using body composition: an individualized, nonparametric approach utilizing large data sets. Obesity 27, 1190-1199 (2019).

21. Fredwall, S. O. et al. High prevalence of symptomatic spinal stenosis in Norwegian adults with achondroplasia: a population-based study. Orphanet J. Rare Dis. 15, 123 (2020).

22. World Health Organization. Waist circumference and waist-hip ratio. Report of a WHO expert consultation, December 8-11 (Geneva, 2008).

23. Williams, B. et al. 2018 ESC/ESH guidelines for the management of arterial hypertension. Eur. Heart J. 39, 3021-3104 (2018).

24. American Diabetes Association. 2nd Classification and diagnosis of diabetes: standards of medical care in diabetes 2018. Diabetes Care 41, S13--S27 (2018).

25. Owen, O. E. et al. Resting metabolic rate and body composition of achondroplastic dwarfs. Medicine 69, 56-67 (1990).

26. Saint-Laurent, C. et al. Early postnatal soluble FGFR3 therapy prevents the atypical development of obesity in achondroplasia. PloS ONE 13, e0195876 (2018).

27. Hoover-Fong, J., Scott, C. I. \& Jones, M. C. Health Supervision for People With Achondroplasia. Pediatrics 145, e20201010 (2020).

28. Balder, J. W. et al. Lipid and lipoprotein reference values from 133,450 Dutch Lifelines participants: age- and gender-specific baseline lipid values and percentiles. J. Clin. Lipidol. 11, 1055-.1064.e1056 (2017).

29. Dhingra, R. \& Vasan, R. S. Age as a risk factor. Med. Clin. N. Am. 96, 87-91 (2012).

30. Hoover-Fong, J. et al. Blood pressure in adults with short stature skeletal dysplasias. Am. J. Med. Genet. Part A 182, 150-161 (2020).

31. Statistics Norway. Tobacco, alcohol and other drugs. https://www.ssb.no/en/ helse/statistikker/royk (2020). 
32. Sims, D. T., Onambele-Pearson, G. L., Burden, A., Payton, C. \& Morse, C. I. Specific force of the vastus lateralis in adults with achondroplasia. J. Appl. Physiol. 124, 696-703 (2018).

33. Sims, D., Onambélé-Pearson, G., Burden, A., Payton, C. \& Morse, C. Whole-body and segmental analysis of body composition in adult males with achondroplasia using dual X-ray absorptiometry. PloS ONE 14, e0213806 (2019).

34. Marcus, R. L., Addison, O., Kidde, J. P., Dibble, L. E. \& Lastayo, P. C. Skeletal muscle fat infiltration: impact of age, inactivity, and exercise. J. Nutr. Health Aging 14, 362-366 (2010)

35. Qin, W., Bauman, W. A. \& Cardozo, C. Bone and muscle loss after spinal cord injury: organ interactions. Ann. NY Acad. Sci. 1211, 66-84 (2010).

36. Mørkedal, B., Romundstad, P. R. \& Vatten, L. J. Informativeness of indices of blood pressure, obesity and serum lipids in relation to ischaemic heart disease mortality: the HUNT-Il study. Eur. J. Epidemiol. 26, 457-461 (2011).

37. Savarirayan, R. et al. Once-daily, subcutaneous vosoritide therapy in children with achondroplasia: a randomised, double-blind, phase 3, placebo-controlled, multicentre trial. Lancet 396, 684-692 (2020).

38. Legeai-Mallet L., Savarirayan R. Novel therapeutic approaches for the treatment of achondroplasia. Bone 2020:115579.

\section{ACKNOWLEDGEMENTS}

We thank the Norwegian Restricted Growth Association (NiK) for their collaboration and support in the project; the Laboratory of Clinical Chemistry, Oslo University Hospital, for performing the blood sample analyses; and Mikael Petersson, AMRA Medical $A B$, for assistance with the statistical analysis. Most of all we thank all the participants for their time and effort in participating in the study. The Norwegian Adult Achondroplasia Study was funded by a grant from the Dam Foundation (project number 2019/FO249324). The MRI investigations in this study were funded by grants from The Norwegian National Advisory Unit on Rare Disorders (NKSD), project numbers 226038 and 226053 . The funding organizations had no part in the design and conduct of the study, collection, management, analysis, and interpreting of the data; preparation, review, or approval of the manuscript; or decision to submit the manuscript for publication.

\section{AUTHOR CONTRIBUTIONS}

S.O.F. has received a consulting fee from BioMarin. J.L. and O.D.L. are stockholders in and employees of AMRA Medical AB. J.L. and O.D.L. have a patent evaluating an individual's characteristics of at least one phenotype pending.

\section{COMPETING INTERESTS}

The authors declare no competing interests.

\section{ETHICS DECLARATION}

The study was approved by the Regional Committee for Medical and Health Research Ethics (REK) South-East, Norway (approval number 2016/2271), and is registered on ClinicalTrials.gov (NCT03780153). The UK Biobank study was approved by the North West Multicenter Research Ethics Committee, UK. All participants gave their informed, written consent prior to participation. The study has been conducted in accordance with the STROBE guidelines for the reporting of observational studies. All authors have read and approved the final manuscript for publication. Clinical trial registration ClinicalTrials.gov identifier NCT03780153.

\section{ADDITIONAL INFORMATION}

Correspondence and requests for materials should be addressed to S.O.F.

Reprints and permission information is available at http://www.nature.com/ reprints

Publisher's note Springer Nature remains neutral with regard to jurisdictional claims in published maps and institutional affiliations.

Open Access This article is licensed under a Creative Commons Attribution-NonCommercial-NoDerivatives 4.0 International License, which permits any non-commercial use, sharing, distribution and reproduction in any medium or format, as long as you give appropriate credit to the original author(s) and the source, and provide a link to the Creative Commons license. You do not have permission under this license to share adapted material derived from this article or parts of it. The images or other third party material in this article are included in the article's Creative Commons license, unless indicated otherwise in a credit line to the material. If material is not included in the article's Creative Commons license and your intended use is not permitted by statutory regulation or exceeds the permitted use, you will need to obtain permission directly from the copyright holder. To view a copy of this license, visit http://creativecommons.org/licenses/by-nc-nd/4.0/.

(c) The Author(s) 2020, corrected publication 2021 